See Article page 202.

\section{Commentary: Toward mechanical circulatory support in univentricular hearts}

\author{
Michael Huebler, MD, Daniel Biermann, MD, and \\ Joerg S. Sachweh, MD
}

Mechanical circulatory support (MCS), either short- or long-term and as a bridge to decision, to recovery, or to heart transplantation, has emerged as standard therapy in adult cardiac care. In pediatric patients, there are more obstacles to overcome; somatic size, growth, complex anatomy, and available hardware limit the options.

In particular, patients with Fontan circulation have a high failure rate in the first 2 decades after Fontan completion. ${ }^{1}$ MCS may be used to maintain or improve a Fontan patient's condition to be eligible for heart transplantation.

The article by Granegger and colleagues ${ }^{2}$ is focused on MCS in pediatric patients with biventricular hearts and univentricular hearts; however, the authors' main direction is toward univentricular support. The EXCOR device (Berlin Heart, Berlin, Germany) served as the pulsatile ventricular assist device (VAD), and the HVAD (Medtronic, Minneapolis, Minn) and HeartMate II (Abbott, Abbott Park, Ill) were the continuous-flow VADs. In the univentricular hearts, cavopulmonary support was established with custommade graft adaptations to redirect systemic venous blood with the EXCOR pump toward the central veins and toward the pulmonary arteries.

In summary, survival was not significantly related to the type of circulation, patient age, or device type. Freedom from adverse events were negatively related to a pulsatile device and lower age; biventricular and univentricular

\footnotetext{
From the Clinic for Children's Heart Medicine, Pediatric Heart Surgery, University Heart and Vascular Center, University Hospital Hamburg-Eppendorf, Hamburg, Germany.

Disclosures: The authors reported no conflicts of interest.

The Journal policy requires editors and reviewers to disclose conflicts of interest and to decline handling or reviewing manuscripts for which they may have a conflict of interest. The editors and reviewers of this article have no conflicts of interest.

Received for publication March 18, 2021; accepted for publication March 19, 2021; available ahead of print April 28, 2021.

Address for reprints: Michael Huebler, MD, Clinic for Children's Heart Medicine, Pediatric Heart Surgery, University Heart and Vascular Center, University Hospital Hamburg-Eppendorf, Martinistrasse 52, 20246 Hamburg, Germany (E-mail: m.huebler@uke.de).

JTCVS Open 2021;6:209-10

2666-2736

Copyright (C) 2021 Published by Elsevier Inc. on behalf of The American Association for Thoracic Surgery. This is an open access article under the CC BY-NC-ND license (http://creativecommons.org/licenses/by-nc-nd/4.0/).

https://doi.org/10.1016/j.xjon.2021.03.013
}

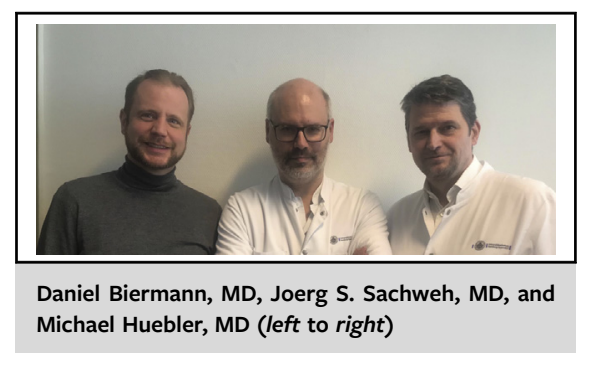

CENTRAL MESSAGE

Mechanical circulatory support

in pediatric patients, particularly

those with univentricular anat-

omy, requires large clinical

studies, evidence-based treat-

ment strategies, and extensive

technical development.

hearts were not different in terms of freedom from treatment-related adverse events. Pulsatile VADs were associated with a higher rate of pump thrombosis. Other adverse events were not different based on pump technology. Thus, in the authors' institution, the tendency is to implant continuous-flow VADs if the anatomic conditions appear suitable. The authors emphasize that their findings are in line with previous reports indicating that outcomes are affected by device and patient factors, which are highly interdependent.

Of note, in this study in all but 1 patient with univentricular physiology, the systemic ventricle was supported; in 1 patient, concomitant cavopulmonary support was attempted. Particularly in cases of dysfunction of the systemic left ventricle and/or subpulmonary failure, further research is needed. Innovative approaches facilitating subpulmonary support with existing or novel devices tailored to patient anatomy and physiology are currently in development.

MCS in children remains an ongoing challenge, particularly in those with univentricular anatomy and physiology, and any report on this issue providing solutions or at least deeper insight is important for the future treatment of our patients. Finally, the need for large prospective multiinstitutional, international studies is obvious, as is the need for generously supported grants for technical development.

\section{References}

1. Shi WY, Yong MS, McGiffin DC, Jain P, Ruygrok PN, Marasco SF, et al. Heart transplantation in Fontan patients across Australia and New Zealand. Heart. 2016;102:1120-6. 
2. Granegger M, Schlöglhofer T, Riebandt J, Schlager G, Skhirtladze-Dworschak K, Kitzmüller E, et al. Mechanical circulatory support in pediatric patients with biventricular and univentricular hearts. J Thorac Cardiovasc Surg Open. 2021;162:202-8.
3. Granegger M, Thamsen B, Hubmann EJ, Choi Y, Beck D, Buechel EV, et al. A long-term mechanical cavopulmonary support device for patients with Fontan circulation. Med Eng Phys. 2019;70:9-18. 